\title{
MIDWIVES' KNOWLEDGE ON INCREASED WEIGHT GAIN AND AMOUNT OF CALORIE CONSUMPTION IN PREGNANCY: A QUALITATIVE STUDY
}

\author{
Dewi Purwaningsih $^{1}$, Indra Supradewi ${ }^{2}$, Debbiyantina ${ }^{3}$ \\ ${ }^{1}$ Midwifery Study Program, Health Polytechnic of Bandung, Ministry of Health \\ ${ }^{2,3}$ Midwifery Study program, Health Polytechnic of Jakarta 3, Ministry of Health
}

\section{INFORMASI ARTIKEL:}

\section{Riwayat Artikel:}

Tanggal diterima: Maret 2020

Tanggal di revisi: Maret 2020

Tanggal di Publikasi: April 2020

Key Word: Weight Gain, Pregnancy, midwifery care

\begin{abstract}
A B S T R A C T
This qualitative study provides an illustration that a midwife must follow the recommendations by the International Confederation of Midwives that the care given to the clients must be holistic. This should also occur in the consultation given during the antenatal visit about the ideal range of weight gain for each individual client along with the recommended amount of calorie intake. Therefore, when the two basic kinds of knowledge are less mastered by midwives, the care will be less holistic. Therefore, collaboration with nutritionists can be done when the midwife has detected what has happened to her client. With the correct mastery of competencies, the practice of midwifery care will become holistic and comprehensive.
\end{abstract}

\section{INTRODUCTION}

The role of midwives in nutrition education during pregnancy is very important, remembering this makes pregnant women know what to consume to maintain the ideal weight of both herself and her fetus. However, the lack of basic knowledge about gestational nutritional needs becomes a particular obstacle for the implementation of this role when midwives face their clients (Arrish, J., Yeatman, H., \& Williamson, M., 2014). Pregnancy outcomes may also become worse when professionals in the field of pregnancy, including midwives, are unable to provide good health education regarding gestational nutritional intake. Because of this, nutritional advice to pregnant women may not be conveyed properly to the client (Begley, 2002).

It is necessary to know that knowledge about nutrition greatly influences the pregnant women's behavior in terms of diet (Fowles and Fowles, 2008). Therefore, many studies have discussed the relationship between

*Korespondensi: nutritional intake during pregnancy and the problems caused, such as low birth weight (Mudor \& Bunyarit, 2013), fetal growth (Osrin \& de L Costello, 2000), children's future behavior (Steenweg-de Graaff et.al., 2014), etc. With the importance of this issue to be revealed, this study can be a recommendation for midwife practitioners to better study nutrition intake, including calories, for the welfare of pregnant women and future generations.

In addition to nutrition in pregnancy, ideal weight gain and calorie consumption during pregnancy can be pivotal to deliver. This is important to know because the improper calorie intake may bring harm to women themselves, such as overweight or underweight (Chang et.al., 2018). This is something that is very important to be known by midwives as a basis for giving advice on ideal body weight and the amount of calorie needed during pregnancy. However, the question that must be revealed in this study is whether or not midwife practitioners who provide health education in pregnancy have mastered the basic knowledge of information on ideal weight gain and the right amount of 
calorie consumption for pregnancy based on BMI.

\section{METHOD}

\section{Sample}

This qualitative study looked for a number of midwife practitioners gathered through snowball sampling (Noy, 2008). The first respondent provided information about the second respondent and so on until the data collected was getting more complete and had been saturated until finally the sampling process was stopped. The inclusion criteria of respondents were midwife practitioners in health center or privately practicing midwives who had practiced for more than 5 years without regard to the age factor of the respondents.

\section{Questions}

The statements made to the respondents are as follows:

1. Have you provided details of normal body weight during pregnancy based on maternal BMI and fetal weight along with the calories needed to achieve this normal state?

2. Do you know the normal weight gain for each trimester of pregnancy based on maternal BMI and fetal weight?

3. Do you know the adequate calorie requirements for each pregnant woman's BMI and fetal weight?

Respondents' answers were written descriptively with revisions based on grammar without changing the meaning of the answers.

\section{RESULT AND DISCUSSION}

For this article, answers from only three respondents were written. This was based on the fact that the answers of all respondents tended to be homogeneous so that the three respondents were considered to represent all respondents collected.

1. Detailed information on normal weight gain and calorie requirements

Midwife A answered that she only gave advice that pregnant women should maintain their weight but did not give detailed details about the intake of food that should be consumed or avoided.

"I usually give advice so that my clients maintain their diet. However, I did not provide complete information, for example, weight gain in trimesters 2 or 3 . I also usually do not provide information on how many calories should be consumed. This should not be done because the client actually needs complete information about calorie intake and normal weight in pregnancy. In my opinion, antenatal classes with several pregnant women who visit the class at once can be more effective in providing detailed information like this."

Midwife B replied that she was accustomed to avoiding detailed information in antenatal consultations with her clients because she felt that detailed information was more appropriate to be conveyed by nutritionists, especially about proper intake in pregnancy so as to control weight gain that was not appropriate.

"I provide information in terms of nutrition only of a general nature, not up to how many calories should be increased in the trimester that is passed. As for nutrition, it might be more appropriate if the nutritionist who delivers it because I am afraid that I would provide guidance on the menu that is not quite right. Thus, to control weight during pregnancy to avoid dangerous overweight, I do not give clients details about what they should consume."

Midwife $\mathrm{C}$ stated that if she provided information such as iron tablet therapy, it was 
easier than information about the amount of calorie intake based on the specific BMI of pregnant women. This required calculations that would later be combined with the right diet to meet the amount of calorie needed in different trimesters. The advice she gave to her clients was only about healthy eating during pregnancy in general.

"Information about certain iron or vitamin tablets might be easier for me to convey to clients. But calorie calculation during pregnancy will be more difficult to convey because it means that I have to calculate the BMI of a pregnant woman and also the estimated fetal weight. Therefore, I always consult to references when I have to deal with the topic discussed to avoid misleading."

2. The normal weight gain for each trimester of pregnancy

Midwife A said that she did not remember the range of normal weight gain during pregnancy, in trimesters 1, 2, and 3. For her, weight gain would be very apparent along with excessive calorie intake. Therefore, she just always reminded his clients to maintain their calorie intake.

"I honestly don't really remember the normal range of weight gain during pregnancy. However, I only remind the clients about the increase in calories they have to consume. Yes, for trimesters 1, 2 or 3, I don't remember the normal increase. Maybe, this is advice to myself that I should study again and memorize that knowledge."

Midwife B also said that she knew about the normal range of weight gain for pregnant women in each trimester when she opened references and she knew how to calculate it. However, she realized that the basic science was very important to remember because the science might be very useful for easier labor. A fetus that was too large, for example, would create difficulties in its birth when it had to pass through the mother's pelvis.

"I know how to calculate when there are references available within my reach. However, yes of course I do not memorize until details. This should be important because nutrition in pregnant women can really determine the outcome of labor. For example, a large fetus may be inconvenient in the birth process so that a cesarean section might be performed. Or if forced to be born vaginally, it is feared that a large perineal tear will occur. In my opinion, indeed we as midwife practitioners must really understand this basic knowledge. Yes, I know how to give recommendation but still I need references near me"

Midwife $\mathrm{C}$ revealed something similar to Midwife A and Midwife B that in order to memorize normal weight gain she had to know the combined formula between pregnant BMIs and estimated fetal weights. This was a little inconvenient for midwives to explain to their clients until finally this was rarely applied.

"The calculation is complicated because it really depends on the BMI of the mother before and after becoming pregnant. The weight gain of a pregnant woman with a normal BMI is certainly different from those with a less or more BMI. We should equip ourselves with this note that must be available on the consultation bench with clients."

3. The adequate calorie requirements for each pregnant woman's BMI and fetal weight

As with questions 1 and 2, the midwives stated that they were not very familiar with the breakdown of the amount of calorie needed for each different pregnant woman. They only remembered a little about calories that had to be added in semesters 2 and 3 but were not specific to the individual cases of pregnant women. 


\section{Midwife A}

"Just like the previous question, I don't remember very well the amount of calorie increase on a case-by-case basis. As I recall, the addition of calories is around $300-350$ calories per day for trimester 2 and about 500 calories for trimester 3 . However, when faced with thin or obese women, I am a little confused to explain."

\section{Midwife B}

"In general I know, but when I have faced case by case, I have had a bit of a hard time explaining to my clients. And honestly, I don't keep calorie counts on my consultation table. I know that this is one of my weaknesses in practice. Hopefully later I can learn in more detail."

\section{Midwife C}

"I do not mention too much on nutrition in detail to my client unless my client shows signs of anemia or something, including prevention. But when it comes to explaining calorie requirements, I mean the amount, frankly, I rarely apply it."

According to Borrelli (2014), one of the criteria for a good midwife is professional competencies. Clinical competence is defined as the combined mastery of knowledge, skills, and attitudes that are applied in clinical practice (Kuvin \& Williams, 2016). This means that midwives in every practice must demonstrate these three things to be called competent midwives. Therefore, when one of the three is not met, the midwife's practice may be detrimental to her clients.

One of the competencies of midwives that must be demonstrated in the antenatal care visit is counseling and consultation about nutritional intake, including calorie intake for normal weight for the pregnant woman and the fetus she is carrying. Knowledge about normal weight gain and the right amount of calorie intake during pregnancy must be mastered well by the midwife accompanied by communication skills in conveying this knowledge to the client and professional attitude as appropriate. This is a holistic delivery of midwifery care (ICM, 2014) so that none of the care is not carried out competently by midwives including basic knowledge about the range of normal weight gain during pregnancy based on BMI of pregnant women and fetal weight they are carrying as well as about the amount of recommended calorie intake.

\section{CONCLUSION}

All clinical care in midwifery should be comprehensively mastered by each midwife, without exception knowledge of the recommended range of weight gain for each individual case and the amount of calorie intake during the pregnancy. When there is one competency that is not properly considered, midwifery care is rendered no longer holistic.

\section{REFERENCE}

Arrish, J., Yeatman, H., \& Williamson, M. (2014). Midwives and nutrition education during pregnancy: A literature review. Women and Birth, 27(1), 2-8. doi:10.1016/j.wombi.2013.02.003

Begley A. Barriers to good nutrient intakes during pregnancy: a qualitative analysis. Nutrition \& Dietetics 2002;59(3):175-80

E. R. Fowles and S. L. Fowles, "Healthy eating during pregnancy: determinants and supportive strategies," Journal of Community Health Nursing, vol. 25, no. 3, pp. 138-152, 2008. 
Mudor, H., \& Bunyarit, F. (2013). A Prospective of Nutrition Intake for Pregnant Women in Pattani, Thailand. Procedia - Social and Behavioral Sciences, 91, 179-184. doi:10.1016/j.sbspro.2013.08.415

Osrin, D., \& de L Costello, A. M. (2000). Maternal nutrition and fetal growth: practical issues in international health. Seminars in Neonatology, 5(3), 209-219. doi:10.1053/siny.2000.0024

Steenweg-de Graaff, J., Tiemeier, H., Steegers-Theunissen, R. P. M., Hofman, A., Jaddoe, V. W. V., Verhulst, F. C., \& Roza, S. J. (2014). Maternal dietary patterns during pregnancy and child internalising and externalising problems. The Generation $\mathrm{R}$ Study. Clinical Nutrition, 33(1), 115-121. doi:10.1016/j.clnu.2013.03.002

Chang, C.-W., Hsu, Y.-Y., Kuo, S.-E., \& Hou, T.-W. (2018). Maternal body weight and diet management system. Contemporary Clinical Trials Communications, 11, 63-68. doi:10.1016/j.conctc.2018.06.001

Noy, C. (2008). Sampling Knowledge: The Hermeneutics of Snowball Sampling in Qualitative Research. International Journal of Social Research Methodology, 11(4), 327344. doi:10.1080/13645570701401305

Borrelli, S. E. (2014). What is a good midwife? Insights from the literature. Midwifery, 30(1), 3-10. doi:10.1016/j.midw.2013.06.019

Kuvin, J. T., \& Williams, E. S. (2016). Defining, Achieving, and Maintaining Competence in Cardiovascular Training and Practice. Journal of the American College of Cardiology, 68(12), 1342-1347. doi:10.1016/j.jacc.2016.05.09

ICM. (2014). Core Document: Philosophy and Model of Midwifery Care 